Article

\title{
Interaction of 2,6,7-Trihydroxy-Xanthene-3-Ones with Iron and Copper, and Biological Effect of the Most Active Derivative on Breast Cancer Cells and Erythrocytes
}

\author{
Přemysl Mladěnka ${ }^{1, *} \mathbb{0}$, Jana Karličcková ${ }^{2}$, Marcel Hrubša ${ }^{1} \mathbb{D}$, Elma Veljović ${ }^{3}$, Samija Muratović ${ }^{3}$, \\ Alejandro Carazo $\left.{ }^{1}{ }^{(}\right)$, Akash Shivling Mali ${ }^{4}$, Selma Špirtović-Halilović ${ }^{3}$, Luciano Saso ${ }^{5}{ }^{(}$, \\ Milan Pour ${ }^{6}$ and Kemal Durić ${ }^{7}$ \\ 1 Department of Pharmacology and Toxicology, Faculty of Pharmacy in Hradec Králové, Charles University, \\ Ak. Heyrovského 1203, 50005 Hradec Králové, Czech Republic; hrubsam@faf.cuni.cz (M.H.); \\ carazofa@faf.cuni.cz (A.C.) \\ 2 Department of Pharmaceutical Botany, Faculty of Pharmacy in Hradec Králové, Charles University, \\ Ak. Heyrovského 1203, 50005 Hradec Králové, Czech Republic; karlickova@faf.cuni.cz \\ 3 Department of Pharmaceutical Chemistry, Faculty of Pharmacy, University of Sarajevo, Zmaja od Bosne 8, \\ 71000 Sarajevo, Bosnia and Herzegovina; elma.veljovic@ffsa.unsa.ba (E.V.); \\ samija.muratovic@ffsa.unsa.ba (S.M.); selma.spirtovic-halilovic@ffsa.unsa.ba (S.Š.-H.) \\ 4 Department of Physiology, Faculty of Science, Charles University, Albertov 2038/6, 12800 Prague—Nové Město, \\ Czech Republic; akash.mali@natur.cuni.cz \\ 5 Department of Physiology and Pharmacology "Vittorio Erspamer", Sapienza University of Rome, \\ Piazzale Aldo Moro 5, 00185 Rome, Italy; luciano.saso@uniroma1.it \\ 6 Department of Organic and Biorganic Chemistry, Faculty of Pharmacy in Hradec Králové, Charles University, \\ Ak. Heyrovského 1203, 50005 Hradec Králové, Czech Republic; pour@faf.cuni.cz \\ 7 Department of Pharmacognosy, Faculty of Pharmacy, University of Sarajevo, Zmaja od Bosne 8, \\ 71000 Sarajevo, Bosnia and Herzegovina; kemal.duric@ffsa.unsa.ba \\ * Correspondence: mladenkap@faf.cuni.cz; Tel.: +420-495-067-295; Fax: +420-495-067-170
}

Received: 18 May 2020; Accepted: 13 July 2020; Published: 15 July 2020

\begin{abstract}
Metal chelators can be potentially employed in the treatment of various diseases, ranging from metal overload to neoplastic conditions. Some xanthene derivatives were previously reported to complex metals. Thus, in a search for a novel iron or copper chelator, a series of 9-(substituted phenyl)-2,6,7-trihydroxy-xanthene-3-ones was tested using a competitive spectrophotometric approach. The most promising compound was evaluated in biological models (breast adenocarcinoma cell lines and erythrocytes). In general, substitution of the benzene ring in position 9 had a relatively low effect on the chelation. Only the trifluoromethyl substitution resulted in stronger chelation, probably via a positive effect on solvation. All compounds chelated iron, but their copper-chelating effect was only minimal, since it was no longer observed under highly competitive conditions. Interestingly, all compounds reduced both iron and copper. Additional experiments showed that the trifluoromethyl derivative protected erythrocytes and even cancer cells against excess copper. In summary, the tested compounds are iron chelators, which are also capable of reducing iron/copper, but the copper-reducing effect is not associated with increased copper toxicity.
\end{abstract}

Keywords: transition metal; chelation; reduction; xanthene; structure-activity relationship 


\section{Introduction}

Iron and copper chelators have significant potential in the treatment of various diseases, ranging from metal overload conditions (repeated blood transfusions, Wilson disease) to cancer [1]. In order to define the ideal properties of chelators for potential therapeutic use, a brief overview of these illnesses and the clinically used chelators, together with their disadvantages, will be provided.

Thalassemia is a common hematological disorder with high prevalence in the Mediterranean area, the Middle East, and many other Asian countries. As a consequence of migration, the prevalence of this disease in formerly non-prevalent countries is increasing [2]. Severe thalassemia requires blood transfusions followed by iron chelation therapy. The current palette of iron chelators includes potent deferoxamine, which needs frequent or continuous parenteral administration, and two oral iron chelators, deferiprone and deferasirox. Deferiprone is a somewhat controversial drug, which is able to induce idiosyncratic agranulocytosis [3,4]. Deferasirox seems to have a better safety profile, but it can cause peptic ulcers and severe hepatic and renal dysfunction in rare cases, and in addition, it might not be always sufficiently active [5]. Furthermore, the selectivity of the current clinically used chelators is being discussed [6]. For these reasons, expanding the selection of the currently available and ideally selective iron chelators is desired.

Wilson disease is a copper disorder, associated with its accumulation in the human body. Its prevalence worldwide is lower than that of thalassemia ( 1 in 10,000/30,000 persons) [7]. The treatment modalities include two oral copper chelators, D-penicillamine and trientine, and zinc in milder cases or in combination regimens. D-penicillamine is a cumbersome drug with many side effects [8] and its copper-chelating effects seem to be weak [9]. Trientine has much better tolerance, but like D-penicillamine, it can worsen neurological symptoms. Currently, ammonium tetrathiomolybdate is being tested in clinical trials [10-12]. Hence, like in the case of iron chelators, novel selective copper chelators are also needed.

It is also well known that both metals are needed for cancer growth and, unsurprisingly, chelators have been tested as anti-cancer compounds $[13,14]$. In the case of tumors, however, rather than depriving tumors of these metals via strong chelators, the redox cycling of the metals by reducing chelators associated with increased production of reactive oxygen species (ROS) is more convenient. It is well known from the literature that some chelators can reduce these metals, and since cancer cells are abundant in copper and iron, the effect of these redox cycling chelators is targeted, in particular, against tumor $[9,15-17]$.

Some xanthone derivatives, which are developed as fluorescent metal probes, were previously reported to form colored complexes with several metals [18-22]. We also reported that the series of xanthones reported herein behaved as potent cytotoxic drugs against cervical, colorectal, hepatocellular and alveolar adenocarcinoma cell lines, with $\mathrm{IC}_{50}$ values mostly in units or tens of $\mu \mathrm{M}$ concentrations [23]. In general, the xanthone scaffold seems to be a suitable base for the development of novel anticancer compounds [24,25]. For this reason, a xanthene core with chelating site(s) was selected as a scaffold for novel chelators. In this study, a series of 2,6,7-trihydroxy-xanthene-3-ones (Figure 1) was tested for their ability to chelate and reduce iron or copper. Since this study aimed at the selection of the most potent chelating compound from this series, and in vitro assessment of its ability to treat metal overload or cancer, the most efficient xanthone was also tested in biological experiments using healthy and cancer cells. Specifically, a strong chelator designed for iron overload diseases should protect erythrocytes against the damaging effects of copper/iron, while a chelator suitable for cancer treatment should increase the toxicity of the metals in cancer cells. For these reasons, the effect of the most active xanthone was tested on both erythrocytes and breast cancer cell lines together with copper or iron ions. 
<smiles>[R]c1c([R3])c([R])c(-c2c3c([R])c(O)c(=O)cc-3oc3cc(O)c(O)cc23)c([R])c1[R4]</smiles>

\begin{tabular}{cccccc}
\hline Compound & $\mathbf{R}_{\mathbf{1}}$ & $\mathbf{R}_{\mathbf{2}}$ & $\mathbf{R}_{\mathbf{3}}$ & $\mathbf{R}_{\mathbf{4}}$ & $\mathbf{R}_{\mathbf{5}}$ \\
\hline $\mathbf{2}$ & $\mathrm{OH}$ & $\mathrm{OCH}_{3}$ & $\mathrm{H}$ & $\mathrm{H}$ & $\mathrm{H}$ \\
\hline $\mathbf{3}$ & $\mathrm{H}$ & $\mathrm{OH}$ & $\mathrm{OH}$ & $\mathrm{H}$ & $\mathrm{H}$ \\
\hline $\mathbf{5}$ & $\mathrm{H}$ & $\mathrm{OCH}_{3}$ & $\mathrm{OH}$ & $\mathrm{OCH}_{3}$ & $\mathrm{H}$ \\
\hline $\mathbf{6}$ & $\mathrm{H}$ & $\mathrm{OCH}_{3}$ & $\mathrm{OH}$ & $\mathrm{NO}_{2}$ & $\mathrm{H}$ \\
\hline $\mathbf{7}$ & $\mathrm{H}$ & $\mathrm{H}$ & $\mathrm{OC}_{2} \mathrm{H}_{5}$ & $\mathrm{H}$ & $\mathrm{H}$ \\
\hline $\mathbf{8}$ & $\mathrm{H}$ & $\mathrm{H}$ & $\mathrm{N}\left(\mathrm{CH}_{3}\right)_{2}$ & $\mathrm{H}$ & $\mathrm{H}$ \\
\hline $\mathbf{9}$ & $\mathrm{H}$ & $\mathrm{H}$ & $\mathrm{CF}_{3}$ & $\mathrm{H}$ & $\mathrm{H}$ \\
\hline $\mathbf{1 0}$ & $\mathrm{H}$ & $\mathrm{H}$ & $\mathrm{NHCOCH}_{3}$ & $\mathrm{H}$ & $\mathrm{H}$ \\
\hline $\mathbf{1 1}$ & $\mathrm{H}$ & $\mathrm{Br}$ & $\mathrm{H}$ & $\mathrm{H}$ & $\mathrm{H}$ \\
\hline $\mathbf{1 2}$ & $\mathrm{Cl}$ & $\mathrm{H}$ & $\mathrm{H}$ & $\mathrm{H}$ & $\mathrm{F}$ \\
\hline
\end{tabular}

Figure 1. Chemical structures of the tested compounds. Numbering is the same as reported in our previous article [23].

\section{Materials and Methods}

\subsection{Reagents and Solutions}

Xanthene-3-on Derivatives

Derivatives of xanthene-3-ones were prepared in accordance with known procedure; the details on the synthesis and characterization were reported previously $[23,26-28]$.

\subsection{Metal Interaction Experiments}

Stock solutions of cupric ions (cupric sulfate pentahydrate, $\mathrm{CuSO}_{4} \cdot 5 \mathrm{H}_{2} \mathrm{O}$ ), ferric ions (ferric chloride hexahydrate, $\mathrm{FeCl}_{3} \cdot 6 \mathrm{H}_{2} \mathrm{O}$ ) and ferrous ions (ferrous sulfate heptahydrate, $\mathrm{FeSO}_{4} \cdot 7 \mathrm{H}_{2} \mathrm{O}$ ) were prepared in water (Milli-Q RG, Merck Millipore, MA, USA), while that of cuprous ions (cuprous chloride, $\mathrm{CuCl}$ ) was prepared in an aqueous solution of $0.1 \mathrm{M} \mathrm{HCl}$ and $1 \mathrm{M} \mathrm{NaCl}$. The corresponding fresh working solutions $(0.25 \mathrm{mM})$ were prepared by dilution either in DMSO (BCS method) or distilled water (hematoxylin and ferrozine method). Hydroxylamine hydrochloride, ferrozine, and bathocuproinedisulfonic acid disodium salt (BCS) were dissolved in distilled water. Hematoxylin was dissolved in DMSO and its working solution $(0.25 \mathrm{mM})$ was usable for no longer than $90 \mathrm{~min}$. All tested xanthones were dissolved in DMSO. Experiments were performed in the following buffers: acetate ( $\mathrm{pH} 4.5$ and 5.5; $15 \mathrm{mM}$ sodium acetate salt, and 27.3 and $2.7 \mathrm{mM}$ acetic acid, respectively) and HEPES (pH 6.8 and 7.5; 15 mM sodium HEPES, and 71.7 and $14.3 \mathrm{mM}$ HEPES, respectively). DMSO was purchased from Avantor Performance Material, (VWR International s.r.o., Stř́ibrná Skalice, Czech Republic), while all other chemicals were purchased from Sigma-Aldrich (St. Louis, MO, USA).

\subsubsection{Iron/Copper Chelation and Reduction Assessment}

These methods are based on the reaction of free metals with an indicator, and the distinct absorption of the resultant complexes in the visible spectra. The indicators are selective for one oxidation state of 
copper or iron. The same methodology can be used for both chelation and reduction when a suitable reductant- hydroxylamine- is added.

The metal chelation experiments were performed in 96-well microplates, at least in duplicate, at room temperature. A Synergy HT Multi-Detection Microplate Reader (BioTec Instruments, Inc., Winooski, VT, USA) was used for taking these measurements. The detailed methodology was described in our original papers $[9,29,30]$.

\subsubsection{Ferrozine Method}

Principle: Ferrozine is a specific indicator forming a magenta-colored complex with ferrous ions.

To evaluate iron chelation, solutions of the tested compounds $(50 \mu \mathrm{L})$ dissolved in DMSO at various concentrations up to $10 \mathrm{mM}$ were mixed in buffers with ferrous or ferric ions for $2 \mathrm{~min}(50 \mu \mathrm{L}, 250 \mu \mathrm{M})$. Ferrozine ( $50 \mu \mathrm{L}, 5 \mathrm{mM})$ was then added in the case of ferrous ions. Hydroxylamine ( $50 \mu \mathrm{L}, 10 \mathrm{mM}$ ) was added prior to ferrozine at $\mathrm{pH} 7.5$ to inhibit ferrous oxidation at this $\mathrm{pH}$. This hydroxylamine solution was also used in the case of total iron chelation at $\mathrm{pH} 4.5$ to reduce the remaining ferric to ferrous ions, which then later formed the previously mentioned complex with ferrozine. Absorbance was measured immediately after the addition of ferrozine and $5 \mathrm{~min}$ later at $562 \mathrm{~nm}$.

To determine the degree of ferric ion reduction, various concentrations of the tested compounds were mixed for 2 min with ferric ions in buffers. Afterwards, ferrozine was added and absorbance was measured both immediately and $5 \mathrm{~min}$ later. Hydroxylamine was used as the positive control (100\% reduction).

\subsubsection{Hematoxylin Method}

Principle: Hematoxylin forms a complex with cupric ions.

Different concentrations of each tested compound were mixed with cupric ions ( $50 \mu \mathrm{L}, 250 \mu \mathrm{M})$ for $2 \mathrm{~min}$ in the presence of a buffer. The mixture was incubated for the next 3 min with the hematoxylin indicator $(50 \mu \mathrm{L}, 250 \mu \mathrm{M})$ in order for the reaction between the non-chelated copper ions and the indicator to occur. Absorbance was measured at this time and again after another $4 \mathrm{~min}$. Different wavelengths were used according to $\mathrm{pH}: 595 \mathrm{~nm}(\mathrm{pH}$ 5.5), $590 \mathrm{~nm}(\mathrm{pH}$ 6.8) and $610 \mathrm{~nm}$ ( $\mathrm{pH}$ 7.5), as reported in our aforementioned paper [9].

\subsubsection{BCS Method}

Principle: The BCS method is analogous to the ferrozine method with the exception that BCS is specific to cuprous ions.

Different concentrations of each tested compound in DMSO up to $10 \mathrm{mM}$ were mixed with cupric or cuprous ions $(50 \mu \mathrm{L}, 250 \mu \mathrm{M})$ and incubated for $2 \mathrm{~min}$ in a buffer. In the case of cupric ions, hydroxylamine ( $50 \mu \mathrm{L}$, varied final concentrations according to $\mathrm{pH}: 1 \mathrm{mM}$ at $\mathrm{pH} 6.8$ and 7.5 while $10 \mathrm{mM}$ at $\mathrm{pH} 4.5$ and 5.5) was added after mixing in order to reduce the non-chelated cupric ions. In the case of cuprous ions, hydroxylamine was added before the copper solution in order to retain copper in its reduced state. Non-chelated copper was then evidenced in both cases by the BCS indicator $(50 \mu \mathrm{L}, 5 \mathrm{mM})$ and absorbance was read immediately and again after $5 \mathrm{~min}$ at $484 \mathrm{~nm}$.

The modified BCS method was used for the determination of cupric ion-reducing potential. Cupric ions were mixed with a tested substance in a buffer without any hydroxylamine for 2 min. The reduced copper ions were later evidenced by BCS. Hydroxylamine was used as the positive control (100\% copper reduction).

\subsubsection{Cancer Cell Viability Assay}

CellTiter $96^{\circledR}$ aqueous non-radioactive cell proliferation assay (Promega, Madison, WI, USA) was performed to evaluate the in vitro effects of $\mathrm{Fe}^{2+}, \mathrm{Cu}^{2+}$ and $4^{\prime}$-trifluoromethyl derivate (9) in breast adenocarcinoma MCF7/S0.5 (parental MCF7 cells adapted to a low-sera environment) and MCF7/182R-6 (derived from MCF7, resistant to the antiestrogen fulvestrant) cell lines. The employed method uses the bioreduction of tetrazolium salt of MTS (3-(4,5-dimethylthiazol-2-yl)-5- 
(3-carboxymethoxyphenyl)-2-(4-sulfophenyl)-2H-tetrazolium) into a colored formazan with an absorbance peak at wavelength $490 \mathrm{~nm}$, which took place only in viable cells via mitochondrial metabolism. Experiments were conducted in accordance with the manufacturer guidelines. The cells were treated with the tested compounds at different concentrations $(1 \mathrm{nM}$ to $750 \mu \mathrm{M})$, metals ( $1 \mathrm{nM}$ to $750 \mu \mathrm{M}$ ) or vehicle (DMSO 0.1\%) for $48 \mathrm{~h}$ in DMEM/F-12 without phenol red media in 96-well plates. Alternatively, xanthone derivate 9 was pre-incubated with the metals prior to being added to cell culture plates and incubated for $48 \mathrm{~h}$. In these experiments, xanthone concentration was maintained constant $(500 \mu \mathrm{M})$ while the metals were tested over a range of concentrations ( $1 \mathrm{nM}$ to $750 \mu \mathrm{M})$ and vice versa. At the end of the treatment, $20 \mu \mathrm{L}$ of MTS reagent was added to each well and incubated for a further $3 \mathrm{~h}$. After this incubation period, absorbance at $490 \mathrm{~nm}$ was measured using a plate reader (Tecan, Mannedorf, Switzerland). The results are expressed as the relative cell viability, considering vehicle (DMSO $0.1 \%$ ) and toxic control (SDS 10\%) as 100\% and $0 \%$ of the response, respectively. All experiments were performed in triplicates and repeated at least three times.

\subsubsection{Erythrocyte Lysis Assay}

This assay was performed according to previous studies with some modifications [31,32]. Blood samples were obtained from adult rats (Wistar Han, Velaz, s.r.o., Czech Republic) by exsanguination into heparinized tubes. The exsanguination was performed by a trained researcher in accordance with The Guide for the Care and Use of Laboratory Animals published by the US National Institutes of Health (8th edition, revised 2011, ISBN-13: 978-0-309-15400-0). The blood was used as a by-product from rats after isolation of aorta, aimed at testing the vasodilatory effect (approval by the Czech Ministry of the Health No. MSMT-34121_2017-2). Afterwards, the blood was centrifuged at $3000 \mathrm{~g}$ and plasma was removed. The erythrocyte fraction was purified by adding saline and further centrifugation. Afterwards, additional heparin (final concentration of $10 \mathrm{IU} / \mathrm{mL}$ in erythrocyte suspension) was added, and this mixture was diluted 10 times with $1 \mathrm{mM}$ glucose solution in saline. Erythrocyte suspension obtained was then used for erythrocyte toxicity evaluation.

$940 \mu \mathrm{L}$ of this suspension was incubated with $10 \mu \mathrm{L}$ of compound No. 9 dissolved in DMSO (different concentrations, final concentration of DMSO was $1 \%$ ) and $50 \mu \mathrm{L}$ of a metal solution (cupric or ferrous sulfate dissolved in saline, at final concentrations of 500 and $2500 \mu \mathrm{M}$, respectively) for $4 \mathrm{~h}$ at $37^{\circ} \mathrm{C}$. The sample was then centrifuged at $7000 \mathrm{~g}$ for $10 \mathrm{~min}$ and $250 \mu \mathrm{L}$ of supernatant was used for the determination of lactate dehydrogenase (LDH) activity, the marker related to metal-induced erythrocyte lysis. The remaining liquid was discarded and a lysis buffer ( $2 \mathrm{mM}$ EDTA, $1 \mathrm{mM}$ dithiotreitol, $1 \%$ Triton $\mathrm{X}, 0.1 \mathrm{M}$ phosphate buffer of $\mathrm{pH} 7.8$ ) was added to the sediment in the same quantity as the removed supernatant. After $20 \mathrm{~min}$ of incubation at room temperature, the samples were treated similarly as the previous supernatant and determined LDH activity was considered to be the marker of the remaining, non-lysed erythrocytes. The protocol used for LDH evaluation was adapted from Chan et al. [32] with minor modifications, erythrocyte suspension was used instead of cell culture and $\beta$-NAD conversion was used to quantify the enzymatic activity. Results were calculated as a percentage of erythrocytes lysed and compared with the positive control, where the solvent DMSO was used instead of the tested compound. Negative control was not treated with the metal, but otherwise elaborated as other samples.

\subsection{Theoretical Calculation}

The energy of compound 9 was minimized using the Chem3D software, which is a part of the ChemDraw package version 18.1 (PerkinElmer, Waltham, MA, USA).

\subsection{Mathematical And Statistical Analysis}

The amount of non-chelated or reduced iron/copper was calculated from the difference between the absorbance of the tested sample (with an indicator) and its corresponding blank (without any 
indicator) divided by the difference of the absorbance of the control sample (the known amount of metal without the tested substance) and its control blank.

Data are expressed as mean \pm SD. The differences of chelation potencies for both iron and copper were checked by $95 \%$ prediction (confidence) intervals of chelation curves. The differences between copper reductions caused by xanthones were assessed by $95 \%$ confidence intervals of the linear regression lines. Difference in cell lysis were tested by Student's t-test. $\mathrm{IC}_{50}$ values were obtained using Hill's equation by nonlinear regression analysis from at least 7-point curves performed in triplicate. For all statistical approaches, GraphPad Prism version 6 for Windows (GraphPad Software, San Diego, CA, USA) was used.

\section{Results}

Firstly, the iron-chelating properties of all the tested compounds were determined under different $\mathrm{pH}$ conditions. In general, the iron chelation properties did not vary substantially among the compounds, and became weaker with a lowering of the $\mathrm{pH}$ (major representatives are shown in Figure 2, other compounds in Figure S1). At pH 7.5, the chelation activity of the majority of the compounds likely corresponded with the chelation stoichiometry of 1:1 (roughly $100 \%$ iron was chelated at $\mathrm{pH} 7.5$ at the ratio of 1:1, see e.g., Figure 2B,C) with the exception of 2 -hydroxy-3-methoxy derivative (2, Figure S2A), which apparently formed complexes with ferrous ions at the stoichiometric ratio of 2:1 (see Figure 2E; at the ratio of 1:1, about $50 \%$ of the iron was chelated). At $\mathrm{pH} 6.8$, the $4^{\prime}$-dimethylamino derivative (8) and $4^{\prime}$-trifluoromethyl derivative (9) were the most efficient, while other compounds had lower effects than these two congeners (Figure S2B). At pH 5.5, the chelating effects of all tested compounds were similar, and it appears that all formed complexes had a stoichiometry of 2:1, compound to iron. The only exception was 8, which was clearly less efficient (Figure S2C). At pH 4.5, again, there were generally no differences between ferrous chelation, with the exception of $\mathbf{9}$, which was the most efficient (Figure S2D). In the case of ferric chelation at the same $\mathrm{pH}$, there were, however, apparently three subgroups. The largest group containing the majority of the compounds comprised the most effective xanthones with a probable stoichiometric ratio of 2:1. A lower effect was observed in the $2^{\prime}$-hydroxy-3'-methoxy, $4^{\prime}$-ethoxy and $3^{\prime}$-bromo derivatives, and $2^{\prime}$-chloro-6'-fluoro $(2,7,11$ and 12). The $4^{\prime}$-dimethylamino congener (8, Figure S2E) was even less efficient. A comparison of the chelation effect of all tested compounds is summarized in Figure 3.

All tested compounds were able to reduce iron at $\mathrm{pH} 4.5$ and partly at $\mathrm{pH} 5.5$. None of them reduced iron at $\mathrm{pH} 6.8$ or 7.5. The reduction curves were bell-shaped in all cases. With the exception of the $4^{\prime}$-dimethylamino derivative, the reducing properties were observed only at low ratios, and were negligible or were abruptly attenuated at ratios higher than 1:1. The maximal reduction reached $50-70 \%$ of added iron in most cases. However, the $4^{\prime}$-hydroxy- $3^{\prime}$-methoxy-5'-nitro derivative (6) and the acetylamino (10) derivatives reached only approximately $30 \%$. Representative compounds are shown in Figure 4, and all other compounds in Figure S3.

The screening of copper chelation activity with hematoxylin showed that all compounds were able to chelate cupric ions at $\mathrm{pH}$ 5.5-7.5 approximately, with the same potency (Figure S4). However, under more competitive conditions, their chelation activity towards both cupric and cuprous ions was negligible (Figures S5 and S6), suggesting a low affinity for copper.

Similar to iron, all compounds were able to reduce cupric ions. In contrast to iron, all xanthones were able to reduce $100 \%$ of the added copper, and their reduction properties did not decrease at higher ratios. There was significant difference in the efficacy of cupric ion reductions at lower ratios. Comparison was performed via 95\% confidence intervals of reduction lines (see an example in the Supplementary Figure S7). The most efficient compound was compound 9 (Figure 5A) followed by derivative 8, which was less efficient at $\mathrm{pH} 4.5,5.5$ and 6.8 . The $3^{\prime}, 4^{\prime}$-dihydroxy derivative (3) was less efficient at $\mathrm{pH} 5.5$ and 7.5 when compared with the $4^{\prime}$-dimethylamino derivative (8). There were no differences between the $3^{\prime}, 4^{\prime}$-dihydroxy derivative (3) and the $4^{\prime}$-hydroxy-3',5'-dimethoxy (5) derivative, which were followed by the less active $4^{\prime}$-ethoxy derivative (7) and $3^{\prime}$-bromo (11) congeners. 
The acetamino derivative (10) had the same activity as the previous two compounds, with the exception of $\mathrm{pH} 4.5$, where it was less efficient. The least efficient compound was the $2^{\prime}$-hydroxy-3'-methoxy derivative (2, Figure 5B). In the case of the $4^{\prime}$-hydroxy- $3^{\prime}$-methoxy-5'-nitro (6) and $2^{\prime}$-chloro-6 $6^{\prime}$-fluoro derivatives (12), the relationship to other compounds was more complicated, particularly in the case of the latter, where the reduction was markedly dependent on $\mathrm{pH}$. The results of the copper reduction experiments are summarized in Figure 6.
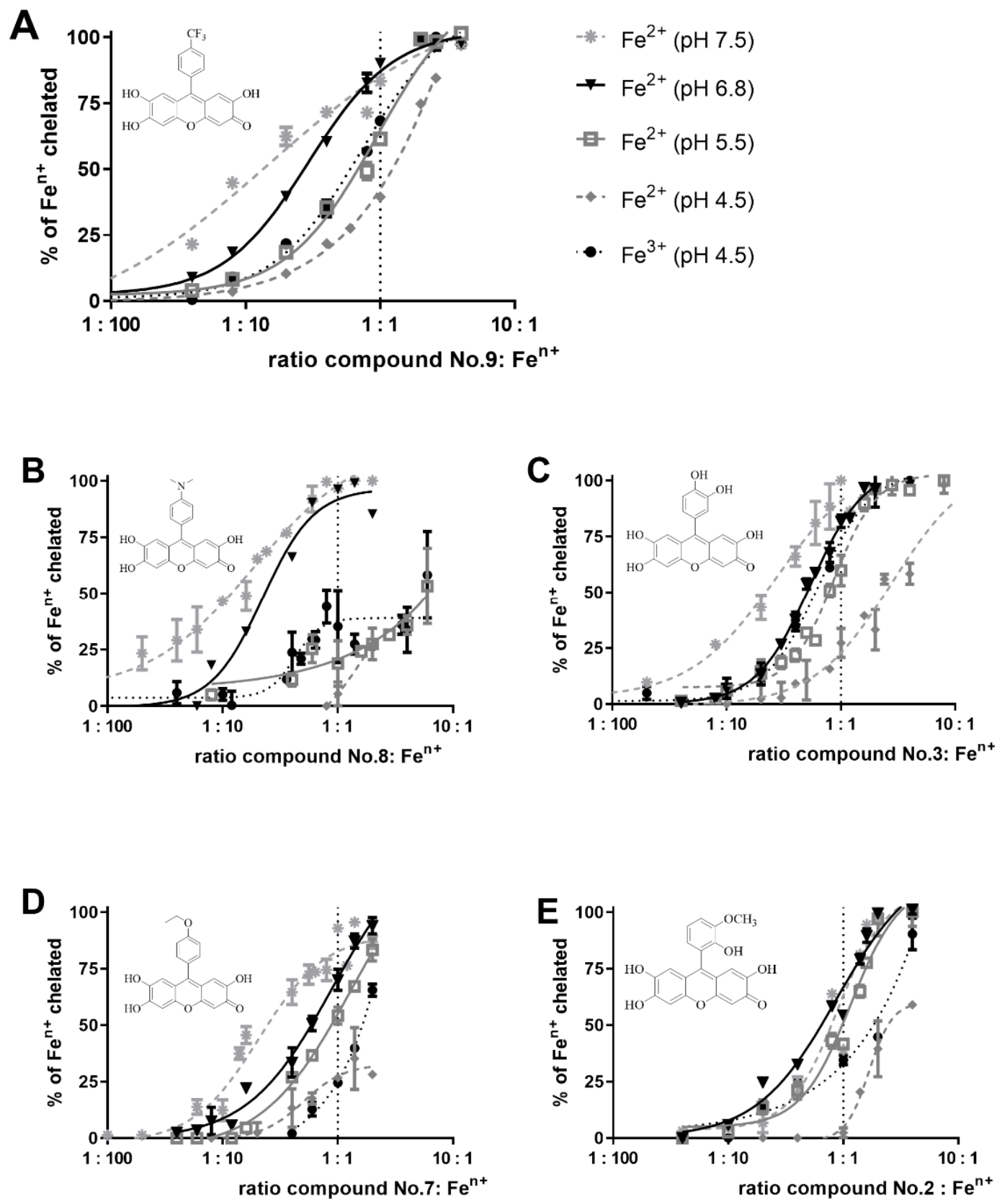

Figure 2. Iron chelation by representative compounds. (A): $4^{\prime}$-trifluoromethyl (9), (B): $4^{\prime}$-dimethylamino (8), (C): 4'-ethoxy (7), (D): 3' $4^{\prime}$-dihydroxy (3) and (E): 2'-hydroxy-3'-methoxy (2). The graphs show different xanthone:iron ions ratios at different $\mathrm{pH}$ conditions. The percentage of chelation on the $y$ axis was calculated using the positive control sample (solvent with iron ions- $100 \%$ remaining metal ions and hence $0 \%$ chelation). The final concentration of the iron ions was $50 \mu \mathrm{M}$ in all cases. 


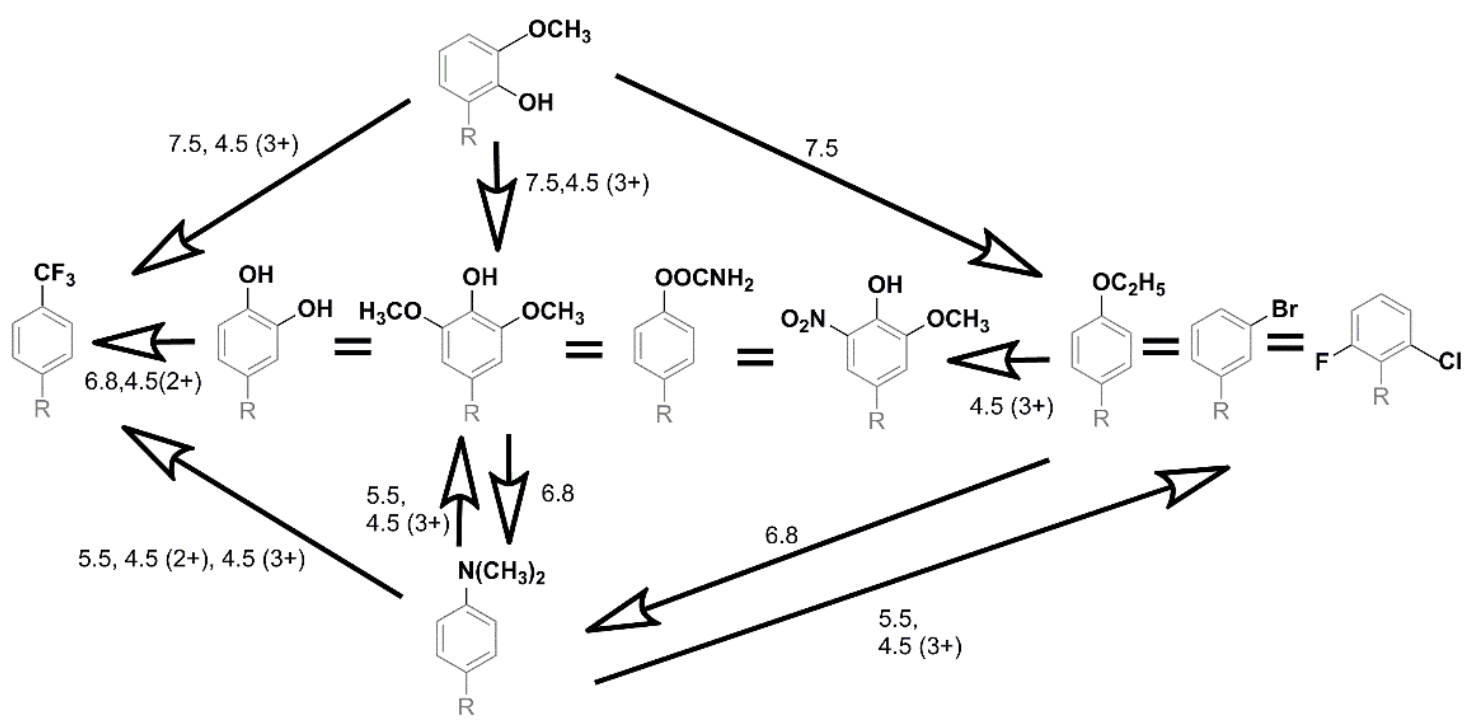

Figure 3. Summary of the differences in iron chelation among the tested compounds. The direction of the arrows shows more active compounds. The numbers represent $\mathrm{pH}$ at which the differences were observed; at $\mathrm{pH} 4.5$, the oxidative state is mentioned in parentheses.
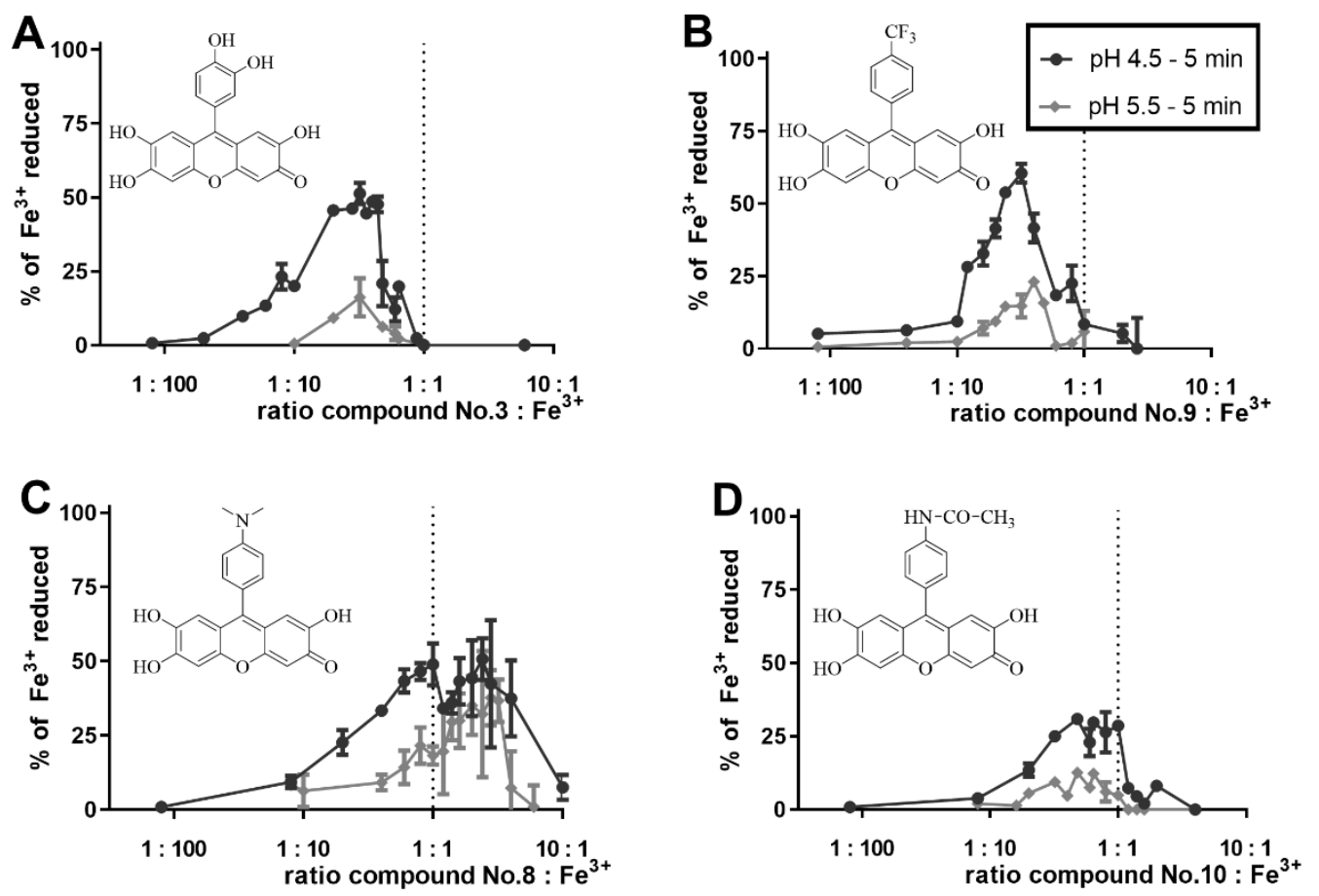

Figure 4. Iron reduction-representative compounds. (A): $3^{\prime}, 4^{\prime}$-dihydroxy (3), (B): $4^{\prime}$-trifluoromethyl (9), (C): $4^{\prime}$-dimethylmino (8) and (D): $4^{\prime}$-acetamido (10) derivatives. Results at higher $\mathrm{pH}$ (negligible reduction) are not shown. The final concentration of iron ions was $50 \mu \mathrm{M}$ in all cases. 

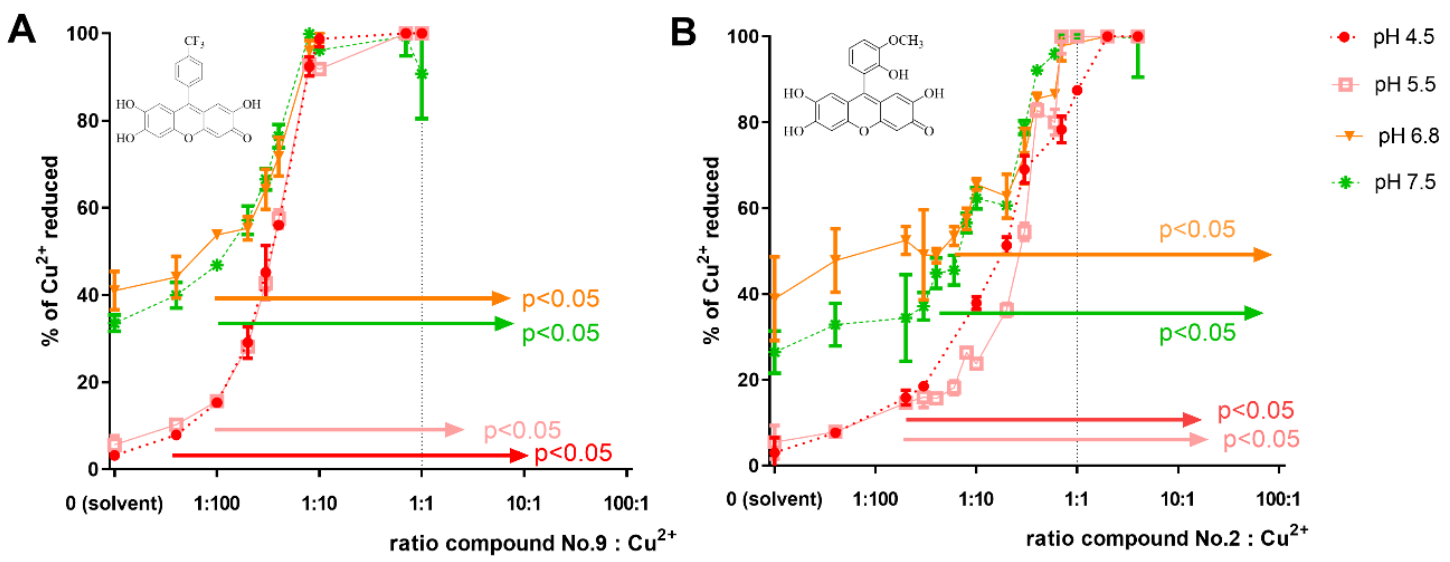

Figure 5. Copper reduction-examples. (A): $4^{\prime}$-trifluoromethyl (9) and (B): $2^{\prime}$-hydroxy-3'-methoxy (2) derivative. The arrows show significance vs. the solvent at corresponding $\mathrm{pH}$. The final concentration of cupric ions was $50 \mu \mathrm{M}$ in all cases.

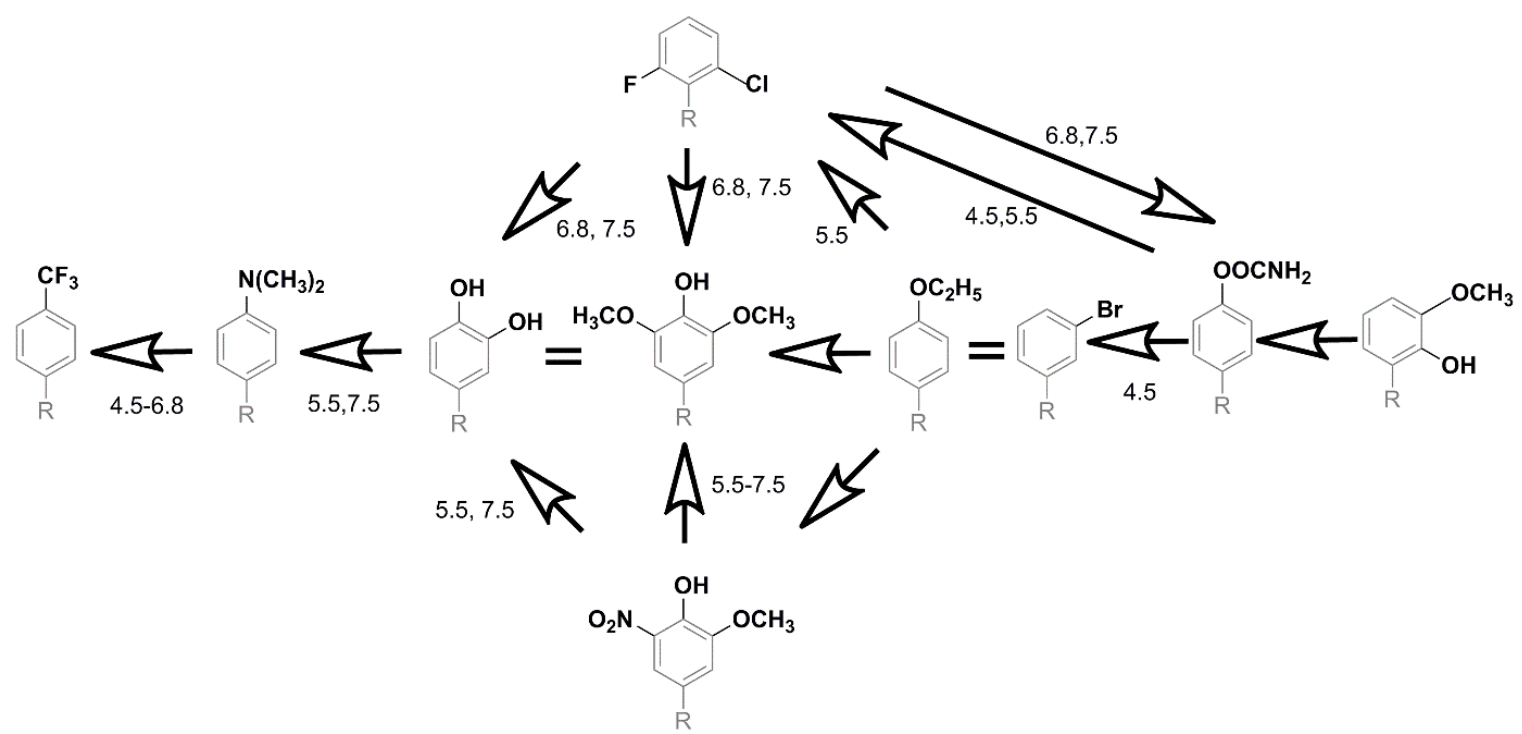

Figure 6. Summary of the differences in copper reduction among the tested compounds. The direction of the arrows shows more active compounds. The numbers represent $\mathrm{pH}$ at which the differences were observed.

As a result of their ability to reduce both metals (see likely scenarios in the Supplementary Data, Figure S8), the xanthones can potentially promote iron- and/or copper-based Fenton reaction and, consequently, increase the cytotoxic effects of these metals. To study the potentially cytotoxic effects toward cancer cells, the most active chelator, the $4^{\prime}$-trifluoromethyl derivate (9), was selected and tested on the adenoma breast cancer cell line (MCF7/S0.5) and fulvestrant-resistant-derived cell line (MCF7/182R-6). We selected this couple of cell lines in order to investigate if the activity of this compound is affected by this specific type of resistance, which is a common consequence observed in cancer. Metals and the xanthone derivative were tested over a range of concentrations, alone and also in combination, and the results were compared to the vehicle control (DMSO $0.1 \%$ ) assigned to $100 \%$ viability. The results showed that although $\mathrm{Fe}^{2+}$ is, as expected, not toxic $\left(\mathrm{IC}_{50}=2611 \mu \mathrm{M}\right)$, the $4^{\prime}$-trifluoromethyl xanthone derivate possessed toxicity similar to that of $\mathrm{Cu}^{2+}$; the $\mathrm{IC}_{50 \text { s }}$ were 218 and $300 \mu \mathrm{M}$, respectively (Table 1). Next, we selected the concentration of $500 \mu \mathrm{M}$ of copper, which was strongly cytotoxic itself, and tested different concentrations of the chelator in order to see the cytotoxicity relationship in relation to the chelator:metal ratio. As shown (Figure 7), the copper 
cytotoxicity was apparently decreased by increasing concentrations of the 4 '-trifluoromethyl derivate. The same experiment was also performed with iron. The addition of iron markedly protected cells against chelator toxicity (Figure 7). The same experiments were also performed with MCF7/182R-6 cells. Here, the $\mathrm{IC}_{50}$ were, as expected, slightly higher than those for MCF7/S0.5; . The pattern of results was similar, but the protection against copper was very mild (Supplementary data Figure S9).

Table 1. Cytotoxicity of $\mathrm{Cu}^{2+}, \mathrm{Fe}^{2+}$ and $4^{\prime}$-trifluoromethylphenyl derivate (9) alone and in combination.

\begin{tabular}{lll}
\hline & \multicolumn{2}{c}{ MCF7/S0.5 } \\
\cline { 2 - 3 } & $\mathrm{IC}_{\mathbf{5 0}}$ & Viability at $\mathbf{1 0} \boldsymbol{\mu M}$ \\
\hline $\mathrm{Cu}^{2+}$ & $299.91 \pm 1.04$ & $98.15 \pm 3.02$ \\
$\mathrm{Fe}^{2+}$ & $>750$ & $94.08 \pm 4.15$ \\
compound No. 9 & $218.27 \pm 1.16$ & $95.03 \pm 6.04$ \\
$\mathrm{Cu}^{2+}(500 \mu \mathrm{M})+$ compound No. 9 & n.a. & $33.24 \pm 3.82$ \\
$\mathrm{Fe}^{2+}(500 \mu \mathrm{M})+$ compound No. 9 & $>750$ & $99.27 \pm 5.13$ \\
\hline
\end{tabular}

n.a.: not applicable.

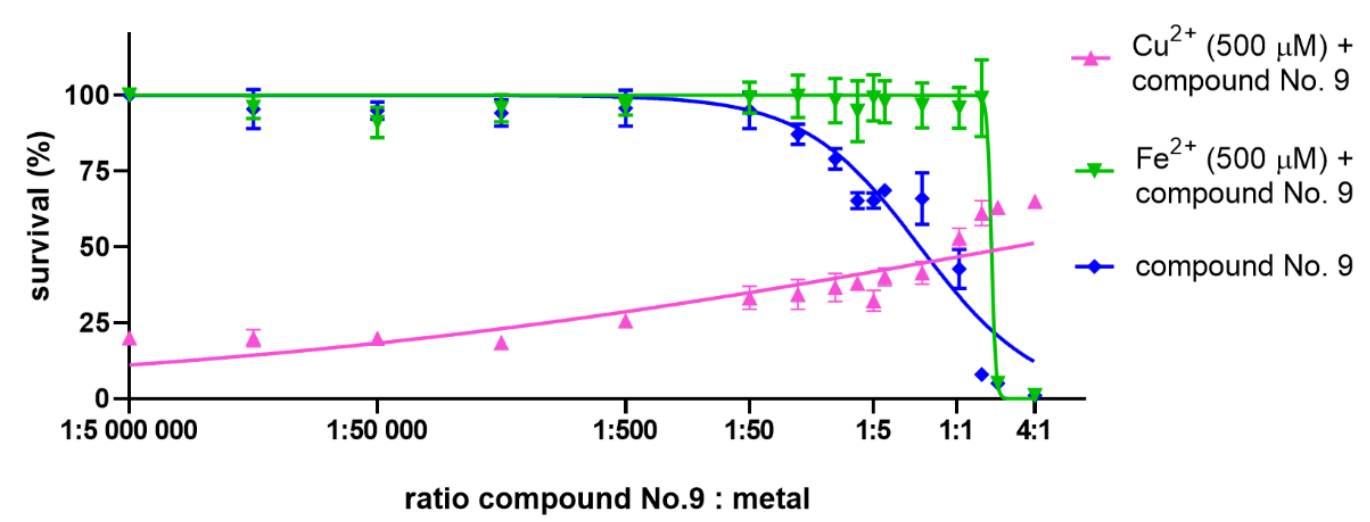

Figure 7. Cytotoxicity of $4^{\prime}$-trifluoromethyl derivate (9) alone and in combination with $\mathrm{Cu}^{2+}$ or $\mathrm{Fe}^{2+}$ at concentration $500 \mu \mathrm{M}$. Viability was determined by cell viability assay after $48 \mathrm{~h}$ treatment in MCF7/S0.5 cells. Vehicle-treated cells were set as $100 \%$ viability.

Following up on the above results, the effects of the most active chelator were also evaluated on rat erythrocytes ex vivo, in order to assess whether the xanthones could protect healthy cells against the toxic effect of the metals. It is well known that copper can cause hemolysis due to its effect on erythrocytes. This undesirable effect can be suppressed by copper chelators [31], while iron is relatively non-toxic. Our previous experiments showed that the percentage of erythrocyte lysis suffers quite significantly from interindividual variability. Hence, we used a higher concentration of copper in order to (at least partly) diminish the variability. $500 \mu \mathrm{M}$ of cupric ions induced lysis in different blood samples in the range of $28 \%$ to $51 \%$ of total red blood cells in the suspension. Regardless of that, the observed protective effects of the tested chelator (when the arithmetic difference between the percentage of the individual chelator sample and the positive blank was used) were homogenous, and in line with the cancer experiments. Substance 9 decreased the hemolysis by $15-20 \%$, depending on the chelator to copper ratio (Figure 8A). Since iron was non-toxic, we used a very high concentration of $2500 \mu \mathrm{M}$. However, this concentration induced a small total lysis of about $1-8 \%$, and this was not different from the negative control without iron. Interestingly, the tested chelator increased iron toxicity by about $10 \%$ (Figure $8 \mathrm{~B}$ ). It should be emphasized that the chelator itself without metals did not evoke any red blood cell toxicity, even at the highest tested concentration of $500 \mu \mathrm{M}$. 

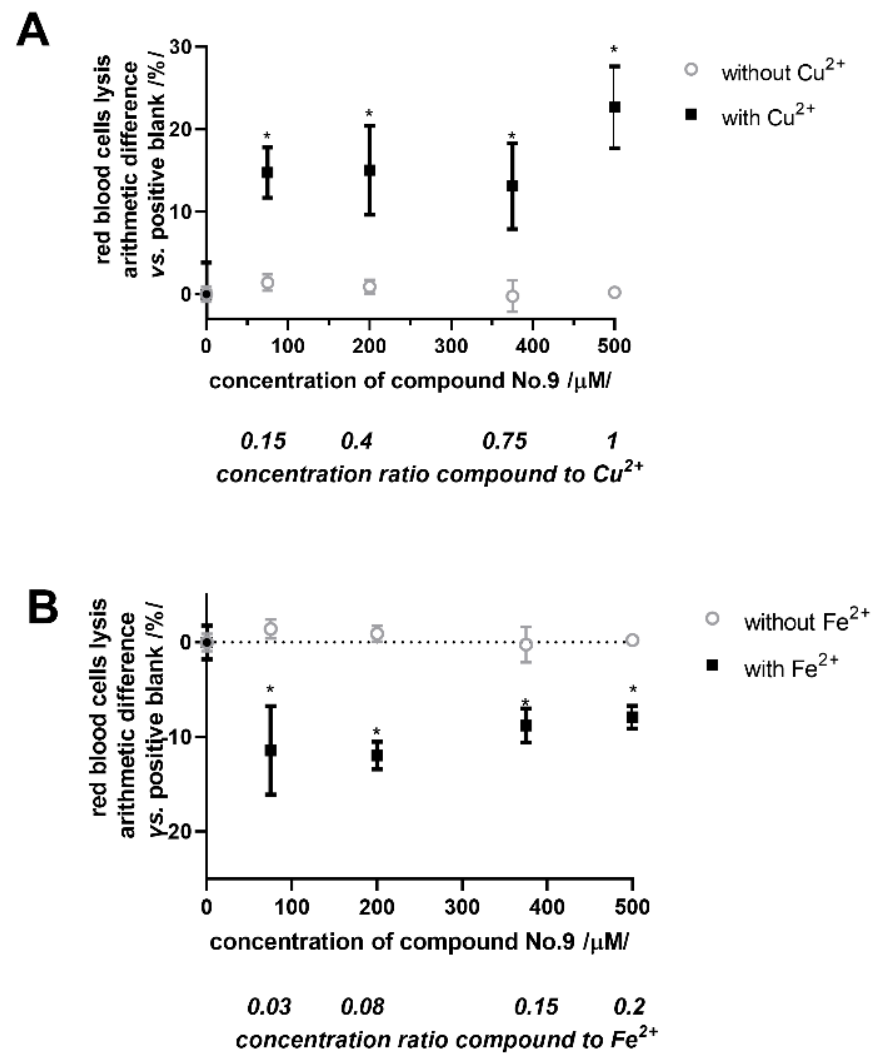

Figure 8. Effect of $4^{\prime}$-trifluoromethyl derivative (9) on copper- and iron-induced red blood cell lysis. (A): The derivative afforded protection against $500 \mu \mathrm{M}$ of copper. (B): The derivative caused an increase in red blood cell lysis, caused by $2.5 \mathrm{mM}$ of iron.

Viability was determined by cell viability assay $48 \mathrm{~h}$ after treatment in MCF7/S0.5 cells. Vehicle-treated cells were set as $100 \%$ viability.

\section{Discussion}

The results of this study confirmed our initial assumption that 2,6,7-trihydroxy-xanthene-3-ones can form complexes with iron and copper. Based on the comparison between hematoxylin (mild competitive conditions, wherein the final concentration of the indicator was equimolar to that of copper) and BCS (the indicator was given in 20-fold excess), it is apparent that these xanthones can also chelate copper. In contrast to iron, however, the complexes are not stable. In the latter case, the iron complexes were stable under 20-fold excess of the indicator ferrozine. The 2-hydroxy-3-one fragment is probably responsible for the chelation, due the higher electron density of the oxo group. Interestingly, the 6,7-dihydroxy fragment and the mentioned 2-hydroxy-3-one site were clearly not able to bind iron or copper simultaneously, since the proposed complexes had a stoichiometry of 1:1 or $2: 1$, xanthone:iron. Further, the functional groups on the benzene ring at position 9 are not involved, since the $3^{\prime}, 4^{\prime}$-dihydroxyderivative (3) was not more potent than the other compounds without this additional chelation site. This outcome was rather surprising since, for example, flavonoids possessing a benzene ring with a catechol substitution can bind more metals than those without this chelation site $[9,33]$. The differences in iron chelation were apparently minor, and seemed to be more related to the possible influence of the substituents on entropic factors (solvation) rather than on the electron density of the xanthene core. In particular, the trifluoromethyl derivative 9 was the most potent chelator. On the other hand, the 2'-hydroxy-3'-methoxy (2) and 2'-chloro-6'-fluoro derivatives (12) decreased chelation. The metal-reducing effect was markedly dependent on the substituent as well. 
As regards the influence of the substitution taking place on the $C(9)$ phenyl ring on iron chelation and $\mathrm{Cu}^{2+}$ reduction, clear-cut relationships are impossible to find. Intuitive chemical reasoning supported by simple MM2 force field calculations (part 2.3, Figure 9) leads to the conclusion that the $C(9)$ phenyl moiety cannot be coplanar with the xanthene scaffold, due to the unfavorable interaction of the $C\left(2^{\prime}\right)$ and $C\left(6^{\prime}\right)$ substituents (including hydrogen) with the xanthene hydrogens at $C(1)$ and $C(8)$. As a consequence, neither the $C(9)$ phenyl nor its substituents can communicate with the xanthene moiety through resonance effects, but only through field effects. Furthermore, since the $\alpha$-hydroxy ketone fragment is responsible for chelation, it is reasonable to assume that only the field effect of the substituents at $C\left(2^{\prime}\right)$ and $C\left(6^{\prime}\right)$ (i.e., the closest ones to the chelation site) may have some influence on metal chelation and reduction.

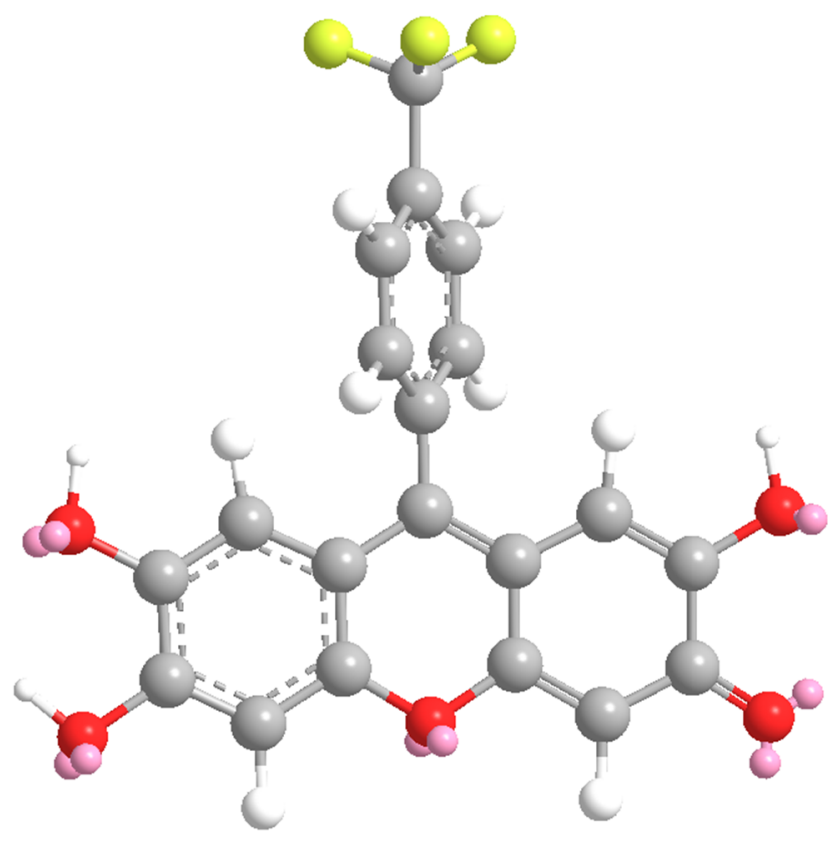

Figure 9. Energy minimization of the 4 '-trifluoromethyl phenyl derivative 9 by MM2 force field method.

For iron chelation, a few notable relationships can be observed. Most interestingly, the $4^{\prime}$-dimethylamino phenyl derivative 8 appears to be the least effective chelator at low $\mathrm{pH}$ values. Similarly, the ortho-substituted phenols $\mathbf{2}$ and $\mathbf{1 2}$ are among the worst chelating compounds under most $\mathrm{pH}$ values, with the exception of $\mathrm{pH}$ 5.5, at which 2'-chloro-6'-fluorophenyl xanthone $\mathbf{1 2}$ became a better chelator than the $4^{\prime}$-dimethylamino derivative 8 . Thus, we can conclude that the low efficiency of the latter most likely resulted from the protonation of the dimethylamino group under acidic conditions, which boosted its electron-withdrawing properties through charge-formation $\left[{ }^{+} \mathrm{N}\left(\mathrm{CH}_{3}\right)_{2}\right]$. Next, both phenol 2 and phenol 12 also bear substituents with a withdrawing $(-I)$ effect $\left(\mathrm{OH}, \mathrm{OCH}_{3}\right.$ or $\mathrm{F}, \mathrm{Cl}$, respectively). In sharp contrast, the $4^{\prime}$-trifluoromethyl phenyl derivative 9 (i.e., strongly electron-withdrawing again) is among the most efficient chelating agents under the majority of $\mathrm{pH}$ conditions studied. This discrepancy, together with the assumption that chelate formation should generally be supported by electron-rich ligands, strongly suggests that the electronic properties of the substituents on the $\mathrm{C}(9)$ phenyl have no direct impact on iron chelation. Their influence on other, no less important factors, such as the solvation of the resultant iron complexes, is probably of much higher significance.

Similar to chelation, copper reduction with concomitant oxidation of the xanthones to $o$-quinones should also be facilitated by electron-rich ligands. In other words, electron-donating substituents should facilitate an electron transfer to $\mathrm{Cu}^{2+}$. However, no straightforward relationship between the electronic properties of the substituents and the ability of the respective xanthone to reduce $\mathrm{Cu}^{2+}$ can be found, either. For example, the $4^{\prime}$-trifluoromethyl phenyl derivative 9 is the most active compound at $\mathrm{pH} 4.5-6.8$, while the $2^{\prime}$-chloro- $6^{\prime}$-fluoro phenyl compound $\mathbf{1 2}$ is the least effective at neutral and 
mildly basic $\mathrm{pH}$ values (6.8 and 7.5). Another $\mathrm{C}\left(2^{\prime}\right)$-substituted phenol, substance 2 , appears to be among the least active compounds as well. Of note, all the 2, 9 and 12 compounds have substituents with $-I$ (withdrawing) effects. Therefore, factors (solvation) other than the electronic effects of the substituents are more important in copper (II) reduction.

In the second part of this study, we selected the most potent compound 9 and tested its suitability for possible future in vivo studies. Our initial assumption, based on the above results, was that iron- and copper-reducing effects can be convenient for a chelator designed for cancer treatment, rather than for metal overload conditions. This speculation seemed to be supported by two arguments: (1) tumors are formed by rapidly growing cells, which require large intakes of iron/copper, and hence are also more susceptible to the iron/copper-based production of ROS via the Fenton chemistry. Increased ROS production with subsequent cellular death can be facilitated by weak chelators, which reduce iron/copper $[15,17,34]$. Indeed, out of our compounds, derivative 9 in particular was the most potent copper reductant in this study. (2) In addition to their metal-chelating effects, this series of xanthones possessed antiplatelet effects [28], and, according to novel investigations, activated platelets increase cancer cell survival and contribute to metastasis $[35,36]$. Indeed, our group has recently demonstrated the solid potential of these compounds to destroy cancer cells in a variety of tumor cell lines. In particular, the most active metal-chelating and -reducing compound from this study - the trifluoromethyl derivative (9)—was also the most potent antiproliferative compound [23]. In order to expand this knowledge, we selected a breast cancer line together with the corresponding resistant alternative, since we had not included such a line in our previous experiments. Very surprisingly, 9 was about 30-200 times less potent in the selected cancer cell line, compared to its effect on cervical, colorectal, hepatocellular and alveolar adenocarcinomas. The difference between the fulvestrant-sensitive and -resistant cancer lines was relatively low (about twofold). Although the explanation for such a huge discrepancy is unclear, our experiments demonstrated that our theoretical assumption was not correct. While the cytotoxicity of the most active compound (9) was observed, the same compound was able to eliminate the cytotoxicity of copper against erythrocytes and conventional cancer cells. The protective effect against $\mathrm{Cu}$-toxicity on resistant cancer cells was lower. This can be regarded as a truly new and unexpected result, suggesting that the metal-reducing activity does not necessarily need to be directly translated into cytotoxicity. Moreover, considering that $500 \mu \mathrm{M}$ of this compound did not cause any increase in red blood cell lysis under normal conditions and its $\mathrm{IC}_{50}$ in relation to cancer cells was more than $250 \mu \mathrm{M}$, the toxicity of this compound under normal conditions seems to be very low. The only questionable issue remains whether iron reduction can stimulate iron toxicity in the red blood cells, but we observed this phenomenon only when using a very excessive concentration of iron $(2.5 \mathrm{mM})$, and such a strong overload is more hypothetical than realistic.

\section{Conclusions}

The 2,6,7-trihydroxyxanthene-3-ones tested are iron chelators with reversible copper-chelating properties. The compounds also reduce iron and copper, and hence were previously assumed to have pronounced cytotoxic effects, thereby being unsuitable for use under metal overload conditions. This assumption was disproved in this study since, on the contrary, the most active compound, $4^{\prime}$-trifluoromethyl derivative $\mathbf{9}$, protected both erythrocytes and cancer cells against copper toxicity. Because the ex vivo toxicity of xanthone 9 is low, the compound can be regarded as a suitable lead for the development of protecting agents for potential use under metal overload conditions. Since its effect on the cancer cells seems to be highly dependent on the selected lines, potential use is likely to be limited to some types of cancers.

Supplementary Materials: There are Supplementary data to this article with additional results. The following are available online at http://www.mdpi.com/2076-3417/10/14/4846/s1, Figure S1: Iron chelation by other compounds not shown in Figure 1, Figure S2: Comparison of iron chelation of representative compounds, Figure S3: Iron reduction-other compounds not shown in Figure 3, Figure S4: Comparison of cupric chelation 
(the hematoxylin assay), Figure S5: Chelation of copper ions assessed by the BCS method. Figure S6: Chelation of cuprous and cupric ions by 2'-chloro-6'-fluoro derivative (12) assessed by the BCS method, Figure S7: Example of comparisons of copper reduction lines with 95\% confidence intervals, Figure S8: Likely scenarios of the interaction of $\mathrm{Fe}^{3+}$ and $\mathrm{Cu}^{2+}$ with tested xanthones, Figure S9: Cytotoxicity of $4^{\prime}$-trifluoromethyl derivate (9) alone and in combination with $\mathrm{Cu}^{2+}$ or $\mathrm{Fe}^{2+}$ at concentration $500 \mu \mathrm{M}$, Table S1: Cytotoxicity of $\mathrm{Cu}^{2+}, \mathrm{Fe}^{2+}$ and $4^{\prime}$-trifluoromethyl derivate (9) alone and in combination

Author Contributions: P.M. designed the work, performed mathematical and statistical analyses, and wrote the article; J.K. and A.S.M. carried out metal interaction experiments; M.P. assessed the chemical structure-activity relationship; E.V., S.M., S.Š.-H. and K.D. synthetized, purified and characterized the compounds; M.H. and A.C. performed cellular experiments, L.S., M.P. and K.D. critically revised the manuscript. All authors have read and agreed to the published version of the manuscript.

Funding: This study was supported by EFSA-CDN (No. CZ.02.1.01/0.0/0.0/16_019/0000841) co-funded by the ERDF. M.H. thanks to the Charles University (SVV 2020/260 414).

Acknowledgments: English language was revised by the agency "the BEST translation".

Conflicts of Interest: The authors declare no conflict of interest.

\section{References}

1. Tam, T.F.; Leung-Toung, R.; Li, W.; Wang, Y.; Karimian, K.; Spino, M. Iron chelator research: Past, present, and future. Curr. Med. Chem. 2003, 10,983-995. [CrossRef]

2. Li, C.K. New trend in the epidemiology of thalassaemia. Best Pract. Res. Clin. Obstet. Gynaecol. 2017, 39, 16-26. [CrossRef] [PubMed]

3. Pontikoglou, C.; Papadaki, H.A. Idiosyncratic drug-induced agranulocytosis: the paradigm of deferiprone. Hemoglobin 2010, 34, 291-304. [CrossRef]

4. Olivieri, N.F.; Brittenham, G.M. Iron-chelating therapy and the treatment of thalassemia. Blood 1997, 89, 739-761. [CrossRef]

5. Neufeld, E.J. Update on iron chelators in thalassemia. Hematol. Am. Soc. Hematol. Educ. Program 2010, 2010, 451-455. [CrossRef]

6. Erdogan, E.; Canatan, D.; Ormeci, A.R.; Vural, H.; Aylak, F. The effects of chelators on zinc levels in patients with thalassemia major. J. Trace Elem. Med. Biol. 2013, 27, 109-111. [CrossRef]

7. Liu, J.; Luan, J.; Zhou, X.; Cui, Y.; Han, J. Epidemiology, diagnosis, and treatment of Wilson's disease. Intractable Rare Dis. Res. 2017, 6, 249-255. [CrossRef]

8. Ishak, R.; Abbas, O. Penicillamine revisited: Historic overview and review of the clinical uses and cutaneous adverse effects. Am. J. Clin. Dermatol. 2013, 14, 223-233. [CrossRef]

9. Riha, M.; Karlickova, J.; Filipsky, T.; Macakova, K.; Hrdina, R.; Mladenka, P. Novel method for rapid copper chelation assessment confirmed low affinity of D-penicillamine for copper in comparison with trientine and 8-hydroxyquinolines. J. Inorg. Biochem. 2013, 123, 80-87. [CrossRef]

10. Tegoni, M.; Valensin, D.; Toso, L.; Remelli, M. Copper chelators: Chemical properties and bio-medical applications. Curr. Med. Chem. 2014, 21, 3785-3818. [CrossRef]

11. Roberts, E.A.; Schilsky, M.L. Diagnosis and treatment of Wilson disease: An update. Hepatology 2008, 47, 2089-2111. [CrossRef] [PubMed]

12. Brewer, G.J. The use of copper-lowering therapy with tetrathiomolybdate in medicine. Expert Opin. Investig. Drugs 2009, 18, 89-97. [CrossRef] [PubMed]

13. Lui, G.Y.; Kovacevic, Z.; Richardson, V.; Merlot, A.M.; Kalinowski, D.S.; Richardson, D.R. Targeting cancer by binding iron: Dissecting cellular signaling pathways. Oncotarget 2015, 6, 18748-18779. [CrossRef] [PubMed]

14. Gupte, A.; Mumper, R.J. Elevated copper and oxidative stress in cancer cells as a target for cancer treatment. Cancer Treat. Rev. 2009, 35, 32-46. [CrossRef] [PubMed]

15. Merlot, A.M.; Kalinowski, D.S.; Richardson, D.R. Novel chelators for cancer treatment: Where are we now? Antioxid. Redox. Signal. 2013, 18, 973-1006. [CrossRef]

16. Macakova, K.; Mladenka, P.; Filipsky, T.; Riha, M.; Jahodar, L.; Trejtnar, F.; Bovicelli, P.; Proietti Silvestri, I.; Hrdina, R.; Saso, L. Iron reduction potentiates hydroxyl radical formation only in flavonols. Food. Chem. 2012, 135, 2584-2592. [CrossRef] 
17. Kalinowski, D.S.; Stefani, C.; Toyokuni, S.; Ganz, T.; Anderson, G.J.; Subramaniam, N.V.; Trinder, D.; Olynyk, J.K.; Chua, A.; Jansson, P.J.; et al. Redox cycling metals: Pedaling their roles in metabolism and their use in the development of novel therapeutics. Biochim. Biophys. Acta 2016, 1863, 727-748. [CrossRef]

18. Dhara, A.; Guchhait, N.; Kar, S.K. A Novel Cr(3+) Fluorescence Turn-On Probe Based on Rhodamine and Isatin Framework. J. Fluoresc. 2015, 25, 1921-1929. [CrossRef]

19. Lv, J.; Zhao, L.J.; Qian, R.C.; Long, Y.T. Off-on fluorescence monitoring of intracellular Ag(+) in single living cells using an $\mathrm{Ag}(+)$-responsive probe. Methods Appl. Fluoresc. 2017, 5, 044003. [CrossRef]

20. Mandal, S.; Banerjee, A.; Ghosh, D.; Mandal, D.K.; Safin, D.A.; Babashkina, M.G.; Robeyns, K.; Mitoraj, M.P.; Kubisiak, P.; Garcia, Y.; et al. An anion induced multisignaling probe for $\mathrm{Hg}(2+)$ and its application for fish kidney and liver tissue imaging studies. Dalton Trans. 2015, 44, 13186-13195. [CrossRef]

21. Guan, M.; Mi, H.; Xu, H.; Fei, Q.; Shan, H.; Huan, Y.; Lv, S.; Feng, G. Study of Fluorescent Imaging of Se (IV) in Living Cells Using a Turn-on Fluorescent Probe Based on a Rhodamine Spirolactame Derivative. J. Fluoresc. 2017, 27, 611-618. [CrossRef]

22. Li, L.; Yuan, L.; Liu, Z. A highly selective turn on fluorescence sensor for $\mathrm{Hg} 2+$ based on rhodamine derivative. J. Fluoresc. 2014, 24, 1357-1361. [CrossRef] [PubMed]

23. Veljović, E.; Špirtović-Halilović, S.; Muratović, S.; Osmanović, A.; Haverić, S.; Haverić, A.; Hadžić, M.; Salihović, M.; Malenica, M.; Šapčanin, A.; et al. Antiproliferative and genotoxic potential of xanthen-3-one derivatives. Acta Pharm. 2019, 69, 683-694. [CrossRef] [PubMed]

24. Li, Z.P.; Lee, H.-H.; Uddin, Z.; Song, Y.H.; Park, K.H. Caged xanthones displaying protein tyrosine phosphatase 1B (PTP1B) inhibition from Cratoxylum cochinchinense. Bioorg. Chem. 2018, 78, 39-45. [CrossRef] [PubMed]

25. Catanzaro, E.; Seghetti, F.; Calcabrini, C.; Rampa, A.; Gobbi, S.; Sestili, P.; Turrini, E.; Maffei, F.; Hrelia, P.; Bisi, A.; et al. Identification of a new tamoxifen-xanthene hybrid as pro-apoptotic anticancer agent. Bioorg. Chem. 2019, 86, 538-549. [CrossRef] [PubMed]

26. Schrick, P.; Geick, K.; Waldvogel, S.R. Reliable Synthesis of 9-Aryl-Substituted 2,6,7-Trihydroxyxanthen-3-ones. Synthesis 2008, 2008, 2211-2216. [CrossRef]

27. Završnik, D.; Veljović, E.; Bajrović, A.; Vrankić, M.; Gržeta, B.; Osmanović, A.; Špirtović-Halilović, S.; Muratović, S. Thermal and Crystallographic Characteristics of Synthesized Xanthen-3-one Derivative. Bull. Chem. Technol. Bosnia Herzeg. 2013, 40, 31-34.

28. Applova, L.; Veljovic, E.; Muratovic, S.; Karlickova, J.; Macakova, K.; Zavrsnik, D.; Saso, L.; Duric, K.; Mladenka, P. 9-(4'-dimethylaminophenyl)-2,6,7-trihydroxy-xanthene-3-one is a Potentially Novel Antiplatelet Drug which Antagonizes the Effect of Thromboxane A2. Med. Chem. 2018, 14, 200-209. [CrossRef]

29. Mladenka, P.; Macakova, K.; Zatloukalova, L.; Rehakova, Z.; Singh, B.K.; Prasad, A.K.; Parmar, V.S.; Jahodar, L.; Hrdina, R.; Saso, L. In vitro interactions of coumarins with iron. Biochimie 2010, 92, 1108-1114. [CrossRef]

30. Catapano, M.C.; Karlickova, J.; Tvrdy, V.; Sharma, S.; Prasad, A.K.; Saso, L.; Chhillar, A.K.; Kunes, J.; Pour, M.; Parmar, V.S.; et al. Mono and dihydroxy coumarin derivatives: Copper chelation and reduction ability. J. Trace Elem. Med. Biol. 2018, 46, 88-95. [CrossRef]

31. Aaseth, J.; Skaug, V.; Alexander, J. Haemolytic activity of copper as influenced by chelating agents, albumine and chromium. Acta Pharmacol. Toxicol. (Copenh) 1984, 54, 304-310. [CrossRef] [PubMed]

32. Chan, F.K.; Moriwaki, K.; De Rosa, M.J. Detection of necrosis by release of lactate dehydrogenase activity. Methods Mol. Biol. 2013, 979, 65-70. [CrossRef]

33. Mladenka, P.; Macakova, K.; Filipsky, T.; Zatloukalova, L.; Jahodar, L.; Bovicelli, P.; Silvestri, I.P.; Hrdina, R.; Saso, L. In vitro analysis of iron chelating activity of flavonoids. J. Inorg. Biochem. 2011, 105, 693-701. [CrossRef]

34. Gaetke, L.M.; Chow-Johnson, H.S.; Chow, C.K. Copper: Toxicological relevance and mechanisms. Arch. Toxicol. 2014, 88, 1929-1938. [CrossRef] [PubMed]

35. Bruno, A.; Dovizio, M.; Tacconelli, S.; Contursi, A.; Ballerini, P.; Patrignani, P. Antithrombotic Agents and Cancer. Cancers 2018, 10, 253. [CrossRef]

36. Naderi-Meshkin, H.; Ahmadiankia, N. Cancer metastasis versus stem cell homing: Role of platelets. J. Cell. Physiol. 2018, 233, 9167-9178. [CrossRef] [PubMed]

(C) 2020 by the authors. Licensee MDPI, Basel, Switzerland. This article is an open access article distributed under the terms and conditions of the Creative Commons Attribution (CC BY) license (http://creativecommons.org/licenses/by/4.0/). 